\title{
Variation in Maternal Responsiveness in Free- Ranging Vervet Monkeys: A Response to Infant Mortality Risk?
}

\section{Citation}

Hauser, Marc D. 1988. Variation in maternal responsiveness in free-ranging Vervet monkeys: A response to infant mortality risk? American Naturalist 131(4): 573-587.

\section{Published Version}

doi:10.1086/284807

\section{Permanent link}

http://nrs.harvard.edu/urn-3:HUL.InstRepos:3512199

\section{Terms of Use}

This article was downloaded from Harvard University's DASH repository, and is made available under the terms and conditions applicable to Other Posted Material, as set forth at http:// nrs.harvard.edu/urn-3:HUL.InstRepos:dash.current.terms-of-use\#LAA

\section{Share Your Story}

The Harvard community has made this article openly available.

Please share how this access benefits you. Submit a story.

Accessibility 


\title{
VARIATION IN MATERNAL RESPONSIVENESS IN FREE-RANGING VERVET MONKEYS: A RESPONSE TO INFANT MORTALITY RISK?
}

\author{
MARC D. HAuser \\ Evolution and Human Behavior Program, University of Michigan, 1524 Rackham Building, \\ Ann Arbor, Michigan 48109
}

Submitted April 3, 1987; Accepted August 13, 1987

Trivers (1972, 1974) argued that the allocation of care must depend on an economic calculation of the costs and benefits to the parent's future reproductive success. Viewed in this light, it is necessary to distinguish between the concepts of parental investment and parental care. Parental investment refers to care that results in benefits to the infant's fitness and costs to the parent's lifetime reproductive potential. In contrast, parental care has been viewed as any positive behavior toward infants, regardless of its cost to the parent's fitness. As a result of this distinction, Trivers predicted that parental investment would be high while offspring were young, since the costs of such investment are low. As the infant develops (e.g., motor skills and nutritional independence) toward independence, however, the benefits of continued investment for the infant decrease and the costs to the parent increase. Thus, parental investment is generally expected to decrease as infants grow older.

Although the distinction between parental investment and parental care is of conceptual importance, parental investment has proved extremely difficult to measure because of the difficulties inherent in calculating the costs to future reproductive success, particularly among long-lived species. In this paper, therefore, I use the term parental care rather than parental investment. Parental care is discussed, however, in light of its costs to the parent's current reproductive decisions.

Captive and field studies of mammalian populations have shown that the amount of parental care generally declines as the infant grows older (e.g., yellow baboons, Altmann 1980; rhesus monkeys, Berman 1980; red deer, Clutton-Brock et al. 1982; domestic cats, Martin 1986; seals, Trillmich 1986). Although this pattern of paternal care is similar across different species, a number of studies have shown that ecological parameters (e.g., climatic differences in bighorn sheep, Berger 1979; nutritional level of ewes, Arnold et al. 1979), social parameters (e.g., rank and maternal "style" in baboons, Ransom and Rowell 1973; Altmann 1980), and demographic parameters (e.g., mother's parity and interbirth interval in rhesus and vervet monkeys, Simpson et al. 1981; Lee, in press) affect 
the amount and timing of care allocation (for reviews, see Low 1978; Carlisle 1982).

Parental care clearly contributes to an offspring's probability of survival, and as a result, such care directly affects a parent's lifetime reproductive success. However, few studies have examined the possibility that variation in the risk of infant mortality guides the pattern of parental care. In this study, playback experiments were designed to test the hypothesis that mothers among free-ranging vervets (Cercopithecus aethiops pygerythrus) living in Amboseli National Park, Kenya, adjust their parental-care allocations in response to temporal variation in infant mortality (i.e., vulnerability). Two interpretations may explain why mothers do not adjust the level of care in response to infant mortality. Either mothers are not sensitive to peaks in infant mortality, or differential allocation of care does not affect the probability of mortality. This experiment simply asks whether mothers alter one type of parental-care allocation over time and whether the pattern of care allocation corresponds to the probability of infant mortality.

In Amboseli National Park, approximately $57 \%$ of all vervet infants fail to survive their first year. This pattern of mortality is common among mammals (Caughley 1966). In addition, infant mortality among Amboseli vervets appears to cluster around two periods, roughly at $4 \mathrm{mo}$ and at $9 \mathrm{mo}$. Although the precise cause of such mortality is unknown, Cheney and Wrangham (1987) suggested that over $70 \%$ of mortality among vervets in Amboseli is due to predation.

\section{METHODS}

Amboseli National Park, located in southern Kenya, is considered a semiarid savanna, receiving approximately $300 \mathrm{~mm}$ of rain per year. From August 1983 to June 1985, six groups of free-ranging vervet monkeys (Cercopithecus aethiops pygerythrus) were observed for over $2250 \mathrm{~h}$ of focal observations. Since 1977, three of the study groups (A, B, C) have been observed intensively; 12 others have been monitored intermittently (Cheney et al. 1988). In 1983, three of the latter groups $(2,3,4)$ were also observed intensively. The entire study area was $3.5 \mathrm{~km}^{2}$, and the mean home-range size was $0.37 \mathrm{~km}^{2}$ (Hauser 1987).

\section{Subjects}

Subjects were 19 mother-infant pairs and 5 control females from four of the six study groups (groups A, B, C, 4; table 1). Playback experiments were conducted on mother-infant pairs during the 1984 and 1985 birth seasons. The date of birth for every infant and the parity of each mother were known in all cases. With the exception of one mother (AF), all females tested were multiparous. Mothers of high, middle, and low dominance rank were equally represented. Rank was determined by approach-retreat interactions (Seyfarth 1980; Lee 1983b).

\section{Experimental Design}

Before experiments began, alarm calls to leopards (Struhsaker 1967; Seyfarth et al. 1980) by the alpha male in each group were tape-recorded using a Sony TCD5M cassette recorder and a Sennheiser directional microphone (K3U power 
TABLE 1

Subjects Tested in the Playback Experiments

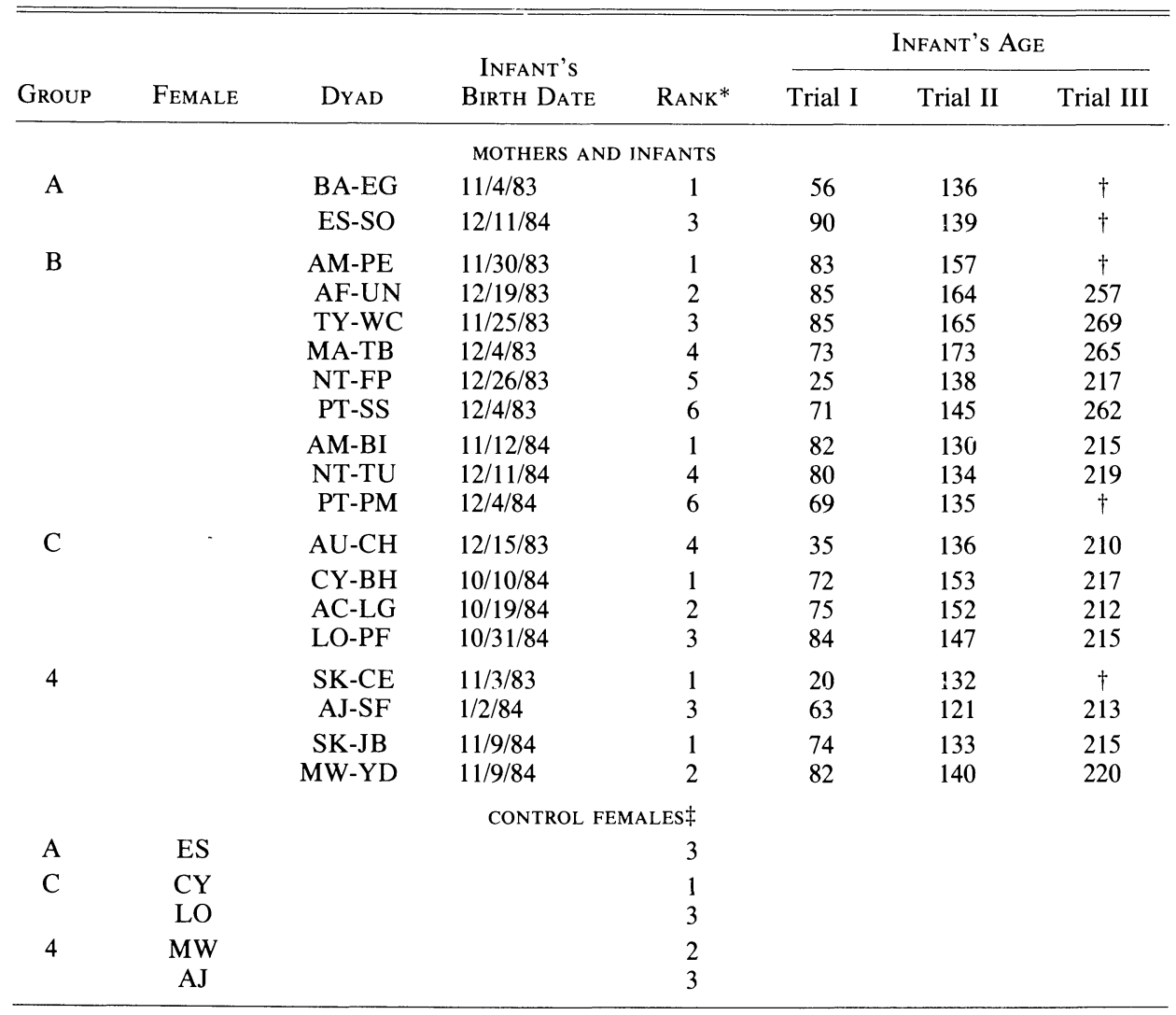

* The highest rank is 1 . For mother and infant subjects, the rank of the mother is given.

$\dagger$ The dyad was not sampled because the infant died.

¥ Female AJ was tested in the 1985 birth season; all other control females were tested in the 1984 birth season.

module, with ME88 recording head and windscreen). All recorded alarm calls occurred in the presence of a leopard that could be spotted by one of the observers. The mean duration of alarm calls was $1.7 \mathrm{~s}(\mathrm{SD}=0.23, n=6)$.

Before a trial began, the following conditions had to be met. First, the mother and infant pair had to be separated from each other by at least $1 \mathrm{~m}$, but by no more than $3 \mathrm{~m}$. Second, they had to be in a position where they probably could not see the male whose call was being used as a stimulus. Third, the mother had to be in a position to see her infant. Fourth, the mother and infant had to be on the ground and at least $5 \mathrm{~m}$ from a mature tree (over $7 \mathrm{~m}$ tall). Since the appropriate response to leopard alarm calls is to run up into a tree and scan the horizon (Struhsaker 1967; Seyfarth et al. 1980), mother and infant pairs were being tested in what appeared to be a dangerous position. And fifth, no naturally occurring alarm calls could have been heard for at least $30 \mathrm{~min}$ before the trial. 
Before each experiment, a speaker was placed in dense foliage, presumably out of sight of the subjects. One observer positioned himself such that he could film the test subjects, and the other observer, who was responsible for starting and stopping the tape stimulus, was stationed approximately $20 \mathrm{~m}$ away from the speaker. Each experiment was filmed for $35 \mathrm{~s}$ before the playback trial and $35 \mathrm{~s}$ afterward. At least 5 days separated each trial on individuals in the same group.

Most mother-infant pairs were tested in three trials (see table 1). Testing periods were selected such that they coincided with intervals preceding both mortality peaks (trials I and III) and between the two peaks (trial II). Additional trials at different periods of infant development or with different types of alarm calls (e.g., eagle alarm calls) could not be run because the animals might habituate. Trial I occurred when the infant was 30-90 days old $(\bar{X}=68.6$ days, mean $\mathrm{SE}=4.7$, $n=19)$, trial II at 120-180 days old ( $\bar{X}=143.7$, mean SE $=143.7, n=19)$, and trial III at $210-270$ days old $(\bar{X}=229.0$, mean $\mathrm{SE}=6.1, n=14)$. Although all mother-infant pairs were tested in the first two trial periods, a number of infants had died by the third trial period.

Two variables were assessed to measure the level of parental care: (1) the proportion of time spent scanning by the mother following the playback; and (2) any physical contact made by the mother with the infant. The latter took a number of forms. For example, some mothers picked up their infants and ran up a tree; other mothers waited for their infants to approach, and then both mother and infant ran up the tree together. For purposes of the analyses presented below, these behaviors have been pooled into one category called protective. Protective behaviors are contrasted with cases in which the mother did not show any overt physical response to the infant.

In addition to interactions between the mother-infant pair, any interaction between the infant and others nearby was also recorded. The identity and proximity of all individuals within $5 \mathrm{~m}$ of the infant were also recorded at the time of the experiment.

To control for the possibility that mothers respond differentially to alarm calls at different times, regardless of infant age, multiparous females without infants were also tested. Tests on these control females had to meet the same criteria set for mothers tested with infants; control females could respond to leopard alarm calls by running up a tree and/or scanning the horizon. Control females were selected from the same groups in which mothers were being tested. In addition, controls were tested during the same times of year as were mothers with infants. This was possible because vervets in Amboseli are seasonal breeders (Cheney et al. 1988). Trial I began in November and ended in February, trial II began in February and ended in April, and trial III began in April and ended in August, excluding the month of July.

RESULTS

Figure 1 presents data about infant mortality gathered since 1977 (Cheney et al., MS). This figure represents data about 131 infants (35 still alive; 67 died in year 1; 


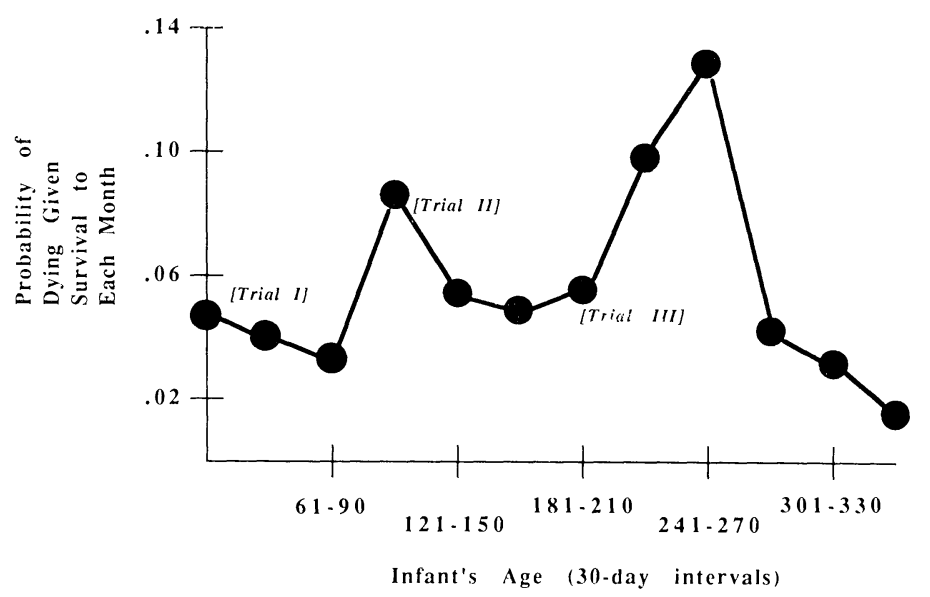

FIG. 1.-The probability of an infant's dying in a particular month given that it survives until that month. Dots, Periods when playback experiments were conducted.

and 29 died after year 1). As previously pointed out, there are two mortality peaks, at 4 mo and at 8-9 mo. Using a Kolmogorov-Smirnov one-sample test, the observed pattern of mortality deviated significantly from the expected $(D=0.583$, $P<0.01)$.

To compare the percentage of time mothers spent scanning in the 1984 and 1985 birth seasons, $t$-tests were used (fig. 2). There were no differences across years for trial I $(t=0.443, \mathrm{df}=17, P>0.05)$, trial II $(t=0.885, \mathrm{df}=17, P>0.05)$, or trial III $(t=0.01$, df $=12, P>0.05)$; consequently, results from the two years have been pooled to test for differences between trials.

A repeated-measures analysis of variance (ANOVA) was used to test for differences in responsiveness between trials. For cases in which dyads were not tested during trial III, they were dropped from this analysis so that the repeated-measures design could be used; 14 mother-infant pairs were entered into this analysis. The Mauchly test $(W)$ for homogeneity of variance within subjects was statistically significant $(W=0.4205$, df $=2, P<0.005)$. Thus, the epsilon correction factor $(\epsilon=0.633)$ was used in the repeated-measures ANOVA. Results from this ANOVA were statistically significant $(F=22.68$, df $=2,26, P<0.0001)$. Thus, each mother had a similar pattern of responsiveness across the three trial periods.

In trial $\mathrm{I}$, the mean percentage of time (s) spent scanning was 55.96 (mean $\mathrm{SE}=$ $5.41, n=19)$. In trial II, the percentage of time spent scanning $(\bar{X}=16.01$, mean $\mathrm{SE}=3.18, n=19 ; t=6.36, P<0.0001)$ decreased significantly. In trial III, the time spent scanning increased $(\bar{X}=31.90$, mean $\mathrm{SE}=5.00, n=14)$ over trial II, and this difference was statistically significant $(t=-2.81, P<0.004)$. Time spent scanning in trial I was also statistically greater than in trial III $(t=3.15, P<$ 0.002 ). Unlike mothers, however, control females did not differ in the percentage of time spent scanning between trials. Thus, maternal responsiveness was highest in tria! I, dropped in trial II, and then rose again in trial III, though not to the level 


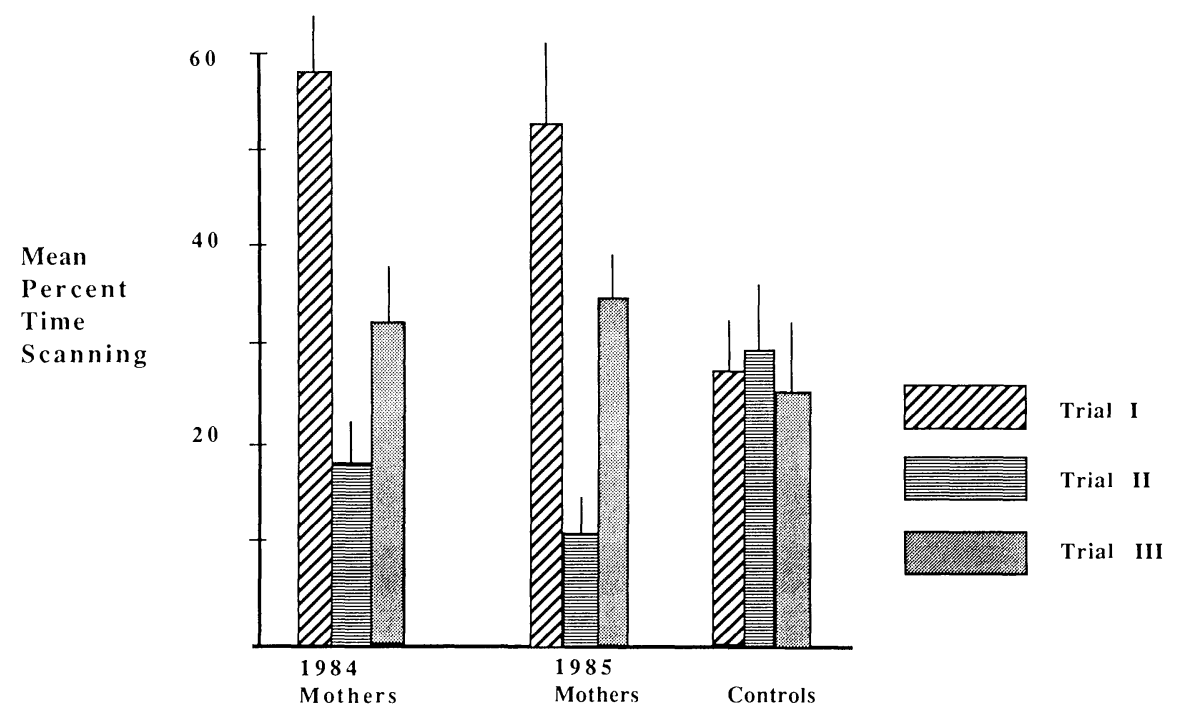

FIG. 2.-The percentage of time (in seconds) during the 1984 and 1985 birth seasons that mothers and control females spent scanning in the period after playback.

seen in trial I. Our data indicate that the pattern of responsiveness shows little variation: $89.5 \%$ of all mothers scanned more in trial I than in trial II, and $83.3 \%$ of all mothers scanned more in trial III than in trial II.

With regard to the mothers' behavioral response toward their infants, $84.2 \%$ showed protective responses during trial I. In trials where the mother did not exhibit protective behavior, she did look toward her infant first $(100 \%)$ before moving toward a tree. Of mothers exhibiting protective behavior, $75 \%$ responded by retrieving their infants and then moving toward a tree. The other mothers were approached by their infants and either huddled with them while scanning in the direction of the speaker or sat next to them and scanned toward the speaker.

In trial II, protective responses declined to $36.8 \%$. For trials in which protective behavior was not exhibited, $83.3 \%$ of the mothers first looked toward their infants and then ran toward a tree. Of mothers responding with protective behavior, $42.8 \%$ retrieved their infants and then ran toward a tree. The other mothers waited for their infants to approach them and then ran toward a tree while the infant followed. In such cases, the infant gained contact with its mother as soon as she stopped moving.

Protective behavior increased in trial III up to a value of $58.3 \%$. Of mothers responding protectively, $57.1 \%$ retrieved their infants and either huddled with them while they scanned or carried them toward a tree. The other mothers waited for their infants to approach and then either huddled with them immediately, ran toward a tree and huddled, or ran toward a tree and then carried them up to a safer place. Mothers who did not exhibit protective behavior first scanned toward their infants on $80 \%$ of the trials and then ran up or toward a tree. In most of these cases, infants followed their mothers toward the tree. The results from the 
mothers' protective behaviors mirror those from their scanning behavior in all three irials.

Results from these playback experiments are further supported by natural observations of mothers' spontaneous response to predator encounters. These observations were obtained during encounters with different vervet predators (i.e., leopards, eagles, snakes, and baboons) when mother-infant pairs were physically separated and on the ground. Before the first mortality peak, mothers exhibited protective behavior in 9 of 11 separate encounters $(n=5$ different mother-infant pairs). Between the mortality peaks, mothers exhibited protective behavior in 3 of 12 encounters $(n=8)$; and before the second mortality peak, mothers showed protective behavior in 4 of 7 encounters $(n=4)$. In addition to supporting the experimental data, these observations extend the generality of the results. Specifically, the pattern of maternalresponsiveness to the presence of leopards appears to be representative of maternal responsiveness to all vervet predators.

The results presented thus far, however, do not permit the conclusion that maternal responsiveness changes as a function of infant age specifically. Although the control females' scanning behavior does not change across trials, it is not yet clear whether the level of responsiveness of mothers and control females differs. To address this problem, independent $t$-tests were run to compare the percentage of time spent scanning by mothers and by control females during the three trial periods. Mothers scanned more than controls in trial I $(t=4.68, P<0.001)$, less than controls in trial II $(t=-7.01, P<0.001)$, and the same amount as controls in trial III $(t=1.41, P>0.05)$. These analyses, however, fail to represent the mothers' (and control females') overall responsiveness, which includes any protective behavior toward her infant and any escape response. Independent $t$-tests were run to compare the mothers' and the control females' overall responsiveness. Overall responsiveness for mothers was calculated as scanning time plus the time spent in protective behavior. Overall responsiveness for control females was calculated by adding scanning time to time spent in escape behavior (i.e., running up into a tree). Mothers were more responsive than controls in trial I ( $t=$ $5.21, P<0.001)$, did not differ from controls in trial II $(t=1.32, P>0.05)$, and were more responsive than controls in trial III $(t=2.95, P<0.02)$. These analyses suggest that mothers respond more than controls before the two mortality peaks and respond to the same degree as the controls between the two peaks.

\section{The Consequences of Different Habitats}

The study groups exhibit striking ecological differences (Wrangham and Waterman 1981; Hauser 1987; Cheney et al. 1988). These differences, particularly in food quality, water availability, and rates of encounters with predators, may have contributed to the pattern of responsiveness by mothers. For example, during some years groups inhabiting the swamp area $(B, C)$ encounter predators at higher rates than groups living in the dry woodland area (groups 2, 3, 4, A; Hauser 1986; Cheney et al. 1988). Although it is unclear whether variation in predator pressure causes differences in infant mortality among groups, one might expect females in the swamp groups to scan for predators at higher rates than females in the dry 


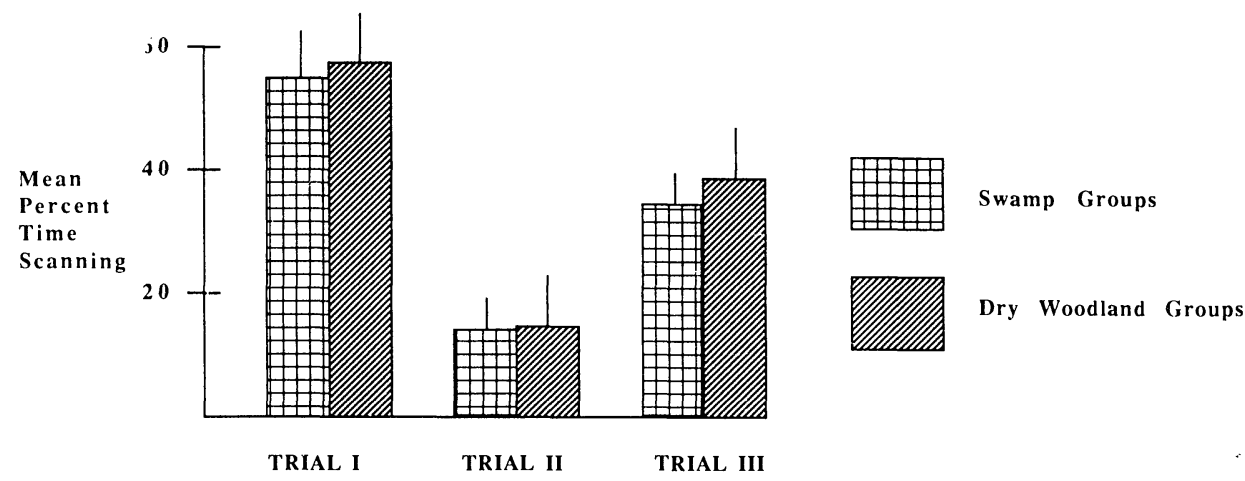

FIG. 3.-A comparison of mother-offspring pairs in the swamp groups and the dry woodland groups for the percentage of time (in seconds) spent scanning during trials I, II, and III.

woodland groups. Moreover, since food quality is lower in the dry woodland groups (Lee 1986; Hauser 1987; Cheney et al. 1988), one might expect individuals in these groups to spend more time foraging, allowing less time for vigilance. To examine these possible confounding factors, mother-infant pairs were divided into swamp and dry woodland groups and the percentage of time spent scanning for each trial tested (fig. 3). Mother-infant pairs from the swamp habitat did not differ significantly from those in the dry woodland habitat for trial I $(t=-0.02$, df $=17$, $P>0.05)$, trial II $(t=-1.41$, df $=17, P>0.05)$, or trial III $(t=0.47$, df $=12$, $P>0.05$ ).

Differences in maternal responsiveness might also be a function of changes in predator-encounter rate that occur over time in the study area. Although predator density in Amboseli does not change seasonally (Seyfarth and Cheney, unpubl. data), the possibility of temporal changes within a given year still exists. If such changes occur, one would predict a positive correlation between the peaks in predator-encounter rate and the peaks in maternal responsiveness. Figure 4 shows the rate at which predators were encountered by month (1983-1985) and the trial periods in which mothers were tested. A single predator encounter was scored whenever the vervets and the observers spotted a predator. This measure underestimates the rate at which vervets encounter large cats (e.g., leopards) and snakes (e.g., pythons) because these predators are more cryptic to human observers than are birds of prey (e.g., martial eagles).

Contrary to the prediction, mothers did not respond more during periods when predator-encounter rates were highest $(r=0.28, n=9, P>0.05)$. In fact, during the period corresponding to trial II, when mothers were the least responsive, predator-encounter rate was highest.

\section{The Consequences of Potential Caretakers}

One additional factor that could influence a mother's responsiveness to leopard alarm calls is the presence of a potential caretaker. For example, if a reliable caretaker is close to the infant, then a mother may be less likely to retrieve her infant upon hearing an alarm call. This decision would be based on the mother's past experience with the caretaker, which suggests that in the mother's absence, 


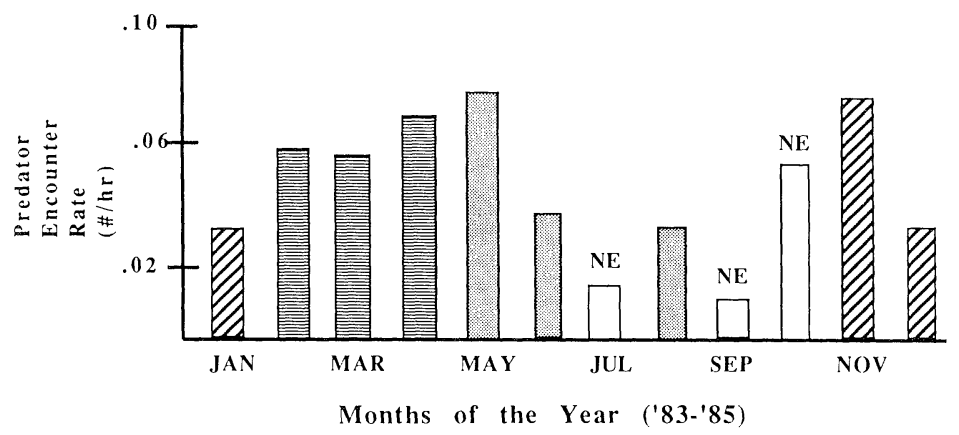

FIG. 4.-Rate (number of predators per hour of observation) at which predators were encountered by month of the year (1983-1985). Hatching, trial I; horizontal stripes, trial II; solid bars, trial III; open bars, no experiments (NE) were conducted.

there is a high probability that the caretaker will retrieve the infant. Instead of operationally defining individuals as reliable or unreliable, the data were examined to reveal how mothers classify caretakers.

Trial I was chosen for analyses because caretaking was most frequent in this period (Lancaster 1972; Whitten 1982; Lee 1983c; Hauser, unpubl. data). When the mother's response to the playback is examined for cases in which the individual closest to the infant (i.e., potential caretaker) was an unrelated juvenile (all females) or yearling (both males and females), mothers retrieved their infants in $85.7 \%$ of the trials ( $n=7$ trials). In contrast, when an unrelated adult female was closest to the infant, mothers retrieved their infants in only $25.0 \%$ of the trials ( $n=8$ trials). The mean percentage of time spent scanning by mothers when unrelated adult females were nearby $(\bar{X}=18.8$, mean $\mathrm{SE}=2.92, n=8)$ was lower than when unrelated juveniles or yearlings were nearby $(\bar{X}=23.57$, mean $\mathrm{SE}=3.56, n=7)$, but this difference was not statistically significant $(t=-1.02$, $P>0.05)$.

These results suggest that maternal responsiveness is adjusted in light of potential caretakers. Although adult female caretakers contacted the infant on only two occasions during experimental conditions, the degree to which they will care for unrelated infants in such contexts cannot be established. Since all of the experiments were conducted while the mother was no more than $3 \mathrm{~m}$ from her infant, the potential caretaker was never the only possible member of the group to protect the infant. Nonetheless, behavioral observations suggest that when naturally occurring alarm calls are given, juvenile and yearling caretakers typically leave infants behind and flee for the trees ( 8 of 12 observations). In contrast, adult caretakers ( 6 of 8 observations) either bring the infant up into the tree or, at least, bring the infant to its mother.

\section{DISCUSSION}

Why were vervet mothers most responsive to leopard alarm calls during trial I (before the first mortality peak) and trial III (primarily before the second mortality peak)? Two possible reasons are differences in the infant's vulnerability to preda- 
tion during development and changes in energetic constraints on the mother as a function of infant growth. Regarding vulnerability, infants are typically in close contact with their mothers during the period corresponding to trial I (Struhsaker 1971; Lee 1983a, in press; Hauser and Fairbanks, in press). On occasion, however, infants are left alone in bushes while their mothers feed. During these situations, infants seem extremely vulnerable to predation given their inability to move independently (Struhsaker 1971; Lee 1981; Hauser, unpubl. data).

During trial II, infants were physically separated from their mothers but in close proximity. The motor skills of these infants improved, however, in the 4-6 mo since trial I. During trial II, infants moved independently of their mothers with relative facility (Struhsaker 1971; Rowell and Richard 1979). Thus, when encounters with predators arise, infants are capable of following their mothers to a safe area. These observations are supported experimentally by cases in which infants followed their mothers up into a tree upon hearing playbacks of leopard alarm calls.

By trial III, infants were almost completely weaned (Lee 1983a, in press) and were typically separated from their mothers for extended periods of time. At this age, however, infants have not yet developed the ability to discriminate between predators and non-predators (Seyfarth and Cheney 1986). As a result, they are potentially more vulnerable to predation.

Mothers may also have adjusted the level of care such that parental care is inversely correlated with energetic constraints (Altmann 1980). That is, if a mother's energetic requirements vary during the period of infant care and if scanning and protective behavior represent costs to the mother's ability to satisfy energetic requirements, then one might expect parental care to vary as a function of changing energetic requirements.

Work by Whitten (1982) on the relationship between maternal body size and infant body size in nonhuman primates suggests that vervet infants, in contrast to most other Old World monkeys, account for a larger proportion of their mother's body size. As a result, mothers incur a relatively high cost by carrying their infants. Given this cost and the current hypothesis, one would predict that rates of food intake would be lowest during trial I, increase in trial II, and then decrease in trial III. Aithough energetic constraints on the mother are undoubtedly important, seasonal changes in nutrient availability (Wrangham and Waterman 1981) make it impossible to generate a straightforward prediction concerning the relationship between food intake rate and parental care. Klein (1978), however, provided evidence that the period of maximum nutritional stress to vervet mothers and infants in this area comes 2-4 mo after birth. Moreover, toward the end of this period of stress, Acacia tortilis trees are typically in flower. The flowers of $A$. tortilis represent a high source of energy (proteins and carbohydrates) for vervets (Klein 1978; Wrangham and Waterman 1981; Altmann et al., MS). Thus, by ingesting large quantities of $A$. tortilis flowers during trial II, mothers could potentially recoup energy lost during trial I. If these flowers enable mothers to recoup energy, then during the period associated with trial III they would have the option of increasing the level of care (i.e., protecting their infants by carrying them up trees). 
Vervet mothers in Amboseli appear to adjust one aspect of their parental care in response to temporal variation in infant mortality and, possibly, changes in energetic constraints. More generally, I suggest that vervet mothers increase the level of such care before periods when infant mortality risk is highest in order to increase the probability of survival during these periods. Although it is difficult to determine the causal relationship between responsiveness and survival, at least three points provide support for the causal direction suggested and the hypothesis in general. First, if one argues that maternal responsiveness to the threat of predation is due to some factor other than infant mortality, then one might expect infant mortality to be highest during periods when maternal responsiveness was lowest. That is, infants would be most susceptible to predation during periods when maternal responsiveness was lowest. Although predator-encounter rates were highest during trial II (fig. 4), when responsiveness was lowest (fig. 2), infant mortality was generally lower during this period than during trial I and much lower than it was during trial III. Thus, mothers (and control females) were not responding to differences in predator-encounter rate that changed over time but, rather, to differences in infant mortality that were probably caused by a host of related variables. This does not rule out the possibility that a mother's responsiveness is influenced by different factors in contexts unlike those of the present experiment (e.g., other vervet predators or when mothers are involved in social interactions; see below). However, it does argue against the possibility that infant mortality was high because mothers were responding less intensely.

Second, the pattern of parental care was similar between years and between groups. The between-year comparison is particularly important because 1984 represented a drought period with low levels of food production in the study area (Hauser 1987). In contrast, 1985 was an average year for rainfall and food production. Given the documented effects of food availability and nutritional status on parental care (e.g., Arnold et al. 1979; Altmann 1980; Hauser and Fairbanks, in press), one might have expected the between-year differences to have had a more dramatic effect on the pattern of responsiveness.

Third, control females did not differ between trial periods in their level of responsiveness. Moreover, mothers' overall responsiveness was similar to that of control females' during trial II, when infant mortality was lowest. Thus, differences in maternal responsiveness were observed before periods of high infant vulnerability. These results imply that, for at least one species, mothers adjust one component of parental care to meet temporal and potentially predictable changes in the probability of their infant's survival.

Some problems are possible with the design and interpretation of this experiment. Throughout the presentation of results, both infant age and the probability of mortality have been assumed to affect maternal responsiveness. Each of these variables might account for different variances of maternal responsiveness. A number of factors preclude testing this hypothesis with multivariate analyses, particularly multiple-regression analyses. First, the number of dyads tested in all three trials was relatively small. Second, because the dependent and independent variables were not linear, it would be necessary to enter curvilinear components into a regression analysis. The small sample size would make it difficult to include 
and interpret such curvilinear components. Third, the experiment was based on a repeated-measures design. Thus, there was a high degree of intercorrelation between scores. Taking these factors into account, constructing a multivariate model without violating most of the assumptions (Tabachnick and Fidell 1985) would be extremely difficult. A final statistical point is that a mean value of mortality was used instead of the continuous data that were available. Although this may obscure gradual developmental changes, insufficient sample sizes precluded the possibility of dividing the subjects into categories that corresponded with the precise pattern of mortality.

A second problem is that parental care has been evaluated only in the context of an infant's susceptibility to predation. Therefore, it is not possible to test the hypothesis that the pattern of care shown here can be generalized to other contexts that affect a mother's tendency to respond (e.g., nutritional constraints, lactational failure, etc.) and that depend on different factors affecting infant survival (e.g., disease, growth, etc.). One could test this hypothesis, for example, by running an experiment to examine whether maternal responsiveness to infant distress calls changes as a function of infant age and of contexts that represent conflicting interests to the mother (e.g., the distress call occurs while the mother is feeding or grooming a high-ranking individual). Tests conducted while mothers were feeding would allow one to determine how the benefits of feeding are weighted against the benefits of providing parental care.

A third problem is that each mother was tested during only three trials, and from the responsiveness of the mothers, arguments were generated about the pattern of parental care. Clearly, three data points cannot completely characterize the parental-care curve. However, one of the primary conclusions to be drawn from this experiment is that one need not expect a gradual decline in parental care over time. Rather, one might expect that in some species, such as vervets, parents may increase the level of care as infants grow older if such care increases the probability of the infants' survival.

What are the proximate cues that enable females to track periods of high infant mortality, and how do mothers assess the relative reliability of a caretaker? One hypothesis is that mothers learn about the probability of mortality by observing irfants at different stages of development over a number of years. This could be tested experimentally by comparing the responsiveness of primiparous and multiparous females. Although females could obtain information about mortality peaks by observing others, direct experience may be more valuable. Similarly, mothers must learn about the relative reliability of caretakers. One would expect younger mothers to be less capable than older mothers in recognizing reliable and unreliable caretakers. Specifically, reliability would be ascertained most accurately by direct experience.

A second explanation is that vervet mothers innately alter their responsiveness as a function of infant development. Proximal cues such as the size of an infant, the infant's proximity to its mother, and/or its dependence would be sufficient to elicit such behavior. This suggests that peaks in infant mortality for this population have been relatively stable and predictable over time. Thus, selection has had sufficient time to shape the pattern of parental-care allocation. 
In conclusion, the playback experiments presented here suggest that vervet mothers in Amboseli modify their parental-care allocations to meet subtle changes in their offspring's probability of mortality. Changes in the allocation of care could be guided by an internal program triggered by maturational changes in the offspring. Alternatively, mothers may learn about their offspring's probability of mortality through direct and/or indirect experience. Understanding how the timing of infant mortality affects the allocation of care in other species should contribute further to our understanding of parental-investment theory.

\section{SUMMARY}

A playback experiment was designed to examine whether maternal responsiveness (i.e., an aspect of parental care) to the threat of predation varies as a function of infant mortality risk in free-ranging vervet monkeys. Results show that mothers responded most intensely to the threat of predation before two periods when infant mortality risk was highest. In contrast, control females, who did not have infants during the test periods, showed no difference in responsiveness to the threat of predation. Vervet mothers appear to increase their parental care before periods of high infant mortality in order to increase their offspring's chances of survival.

\section{ACKNOWLEDGMENTS}

For permission to work in Amboseli National Park, I would like to thank the National Research Council for Science and Technology, the Office of the President, and the Ministry of Wildlife and Tourism of Kenya. For support and help while in Amboseli, I would like to thank the wardens and rangers. J. Else and M. Buteyo of the Institute of Primate Research were invaluable with regard to all aspects of my research. B. Musyoka Nzuma, my field assistant, placed speakers, observed animals, and watched carefully for buffalo. I thank J. Altmann and P. Lee for useful discussions in the field. Critical comments on the manuscript were provided by N. Blurton Jones, D. Cheney, L. Fairbanks, R. Gibson, J. Mitani, R. Seyfarth, and J. Silk. Three anonymous reviewers also provided extremely valuable comments on various aspects of the manuscript. Major funding for this research was provided by a grant from the National Science Foundation to D. Cheney and R. Seyfarth (BNS 82-15039). I also thank the Wenner-Gren Foundation, Sigma $\mathrm{Xi}$, and the University of California for additional support.

\section{LITERATURE CITED}

Altmann, J. 1980. Baboon mothers and infants. Harvard University Press, Cambridge, Mass.

Arnold, G. W., S. R. Wallace, and R. A. Maller. 1979. Some factors involved in natural weaning processes in sheep. Appl. Anim. Ethol. 5:43-50.

Berger, J. 1979. Weaning conflict in desert and mountain bighorn sheep (Ovis canadensis): an ecological interpretation. Z. Tierpsychol. 50:188-200.

Berman, C. M. 1980. Mother-infant relationships among free-ranging rhesus monkeys on Cayo Santiago: a comparison with captive pairs. Anim. Behav. 28:860-873. 
Carlisle, T. R. 1982. Brood success in variable environments: implications for parental care allocation. Anim. Behav. 30:824-836.

Caughley, G. 1966. Mortality patterns in mammals. Ecology 47:906-918.

Cheney, D. L., and R. W. Wrangham. 1987. Predation. Pages 227-239 in B. B. Smuts, D. L. Cheney, R. M. Seyfarth, R. W. Wrangham, and T. T. Struhsaker, eds. Primate societies. University of Chicago Press, Chicago.

Cheney, D. L., R. M. Seyfarth, S. J. Andelman, and P. C. Lee. 1988. Reproductive success in vervet monkeys. In T. H. Clutton-Brock, ed. Reproductive success. University of Chicago Press, Chicago (in press).

Clutton-Brock, T. H., F. E. Guinness, and S. D. Albon. 1982. Red deer: behavior and ecology of two sexes. University of Chicago Press, Chicago.

Hauser, M. D. 1986. Male responsiveness to infant distress calls in free-ranging vervet monkeys. Behav. Ecol. Sociobiol. 19:65-71.

1987. Behavioral ecology of free-ranging vervet monkeys: proximate and ultimate levels of explanation. Ph.D. diss. University of California, Los Angeles.

Hauser, M. D., and L. A. Fairbanks. In press. Mother-offspring conflict in vervet monkeys: variation in response to ecological factors. Anim. Behav.

Klein, D. J. 1978. The diet and reproductive cycles of a population of vervet monkeys. Ph.D. diss. New York University, New York.

Lancaster, J. B. 1972. Play-mothering: the relation between juvenile females and young infants among free-ranging vervet monkeys. Pages 486-513 in I. DeVore, ed. Primate behavior: field studies of monkeys and apes. Holt, Rinehart \& Winston, New York.

Lee, P. C. 1981. Ecological and social influences on development of vervet monkeys (Cercopithecus aethiops). Ph.D. diss. Cambridge University, Cambridge.

1983a. Early infant development and maternal care in free-ranging vervet monkeys. Primates 25:36-47.

1983b. Context-specific unpredictability in dominance interactions. Pages 35-44 in R. A. Hinde, ed. Primate social relationships. Sinauer, Sunderland, Mass.

1983c. Caretaking of infants and mother-infant relationships. Pages 145-151 in R. A. Hinde, ed. Primate social relationships. Sinauer, Sunderland, Mass.

1986. Environmental influences on development: play, weaning and social structure. Pages 227-238 in J. G. Else and P. C. Lee, eds. Primate ontogeny, cognition and social behavior. Cambridge University Press, Cambridge.

In press. Nutrition, fertility and maternal investment in primates. J. Zool. (Lond.).

Low, B. S. 1978. Environmental uncertainty and the parental strategies of marsupials and placentals. Am. Nat. 112:197-213.

Martin, P. 1986. An experimental study of weaning in the domestic cat. Behaviour 99:221-249.

Ransom, T. W., and T. E. Rowell. 1973. Early social development of feral baboons. Pages 105-144 in F. E. Poirier, ed. Primate socialization. Random House, New York.

Rowell, T. E., and S. M. Richards. 1979. Reproductive strategies of some African monkeys. J. Mammal. 60:58-69.

Seyfarth, R. M. 1980. The distribution of grooming and related behaviours among adult female vervet monkeys. Anim. Behav. 28:798-813.

Seyfarth, R. M., and D. L. Cheney. 1986. Vervet monkey vocal development. Anim. Behav. 34:16401658.

Seyfarth, R. M., D. L. Cheney, and P. Marler. 1980. Vervet monkey alarm calls. Anim. Behav. 28:1070-1094

Simpson, M. J. A., A. E. Simpson, J. Hooley, and M. Zunz. 1981. Infant-related influences on birth intervals in rhesus monkeys. Nature (Lond.) 290:49-51.

Struhsaker, T. T. 1967. Ecology of vervet monkeys (Cercopithecus aethiops) in the Masai-Amboseli Game Reserve, Kenya. Ecology 48:891-904.

1971. Social behaviour of mother and infant vervet monkeys (Cercopithecus aethiops). Anim. Behav. 19:233-250.

Tabachnick, R., and G. Fidell. 1985. Using multivariate analyses. Academic Press, New York. 
Trillmich, F. 1986. Maternal investment and sex-allocation in the Galápagos fur seal, Arctocephalus galapagoensis. Behav. Ecol. Sociobiol. 19:157-168.

Trivers, R. L. 1972. Parental investment and sexual selection. Pages 136-179 in B. Campbell, ed. Sexual selection and the descent of man, 1871-1971. Aldine, Chicago. 1974. Parent-offspring conflict. Am. Zool. 14:249-265.

Whitten, P. L. 1982. Female reproductive strategies among vervet monkeys. Ph.D. diss. Harvard University, Cambridge, Mass.

Wrangham, R. W., and P. G. Waterman. 1981. Feeding behaviour of vervet monkeys on Acacia tortilis and Acacia xanthophloea: with special reference to reproductive strategies and tannin products. J. Anim. Ecol. 50:715-731. 